\title{
Firm-Level Political Risk and Asymmetric Volatility
}

\author{
Goodness C. Aye ${ }^{*}$, Mehmet Balcilar ${ }^{* *}$, Riza Demirer ${ }^{* * *}$ and Rangan Gupta ${ }^{* * *}$
}

\begin{abstract}
This paper examines whether proxies of political risk exposure at the firm-level can predict the aggregate stock market volatility. Utilizing a nonparametric causality-in-quantiles test which not only guards against misspecification due to nonlinearity, but also tests for causality over the entire conditional distribution of the realized volatilities, we show that political risk exposure can serve as a strong predictor of bad realized volatility, while the causal effects are non-existent in the case of overall and good realized volatilities. Our findings provide novel insight to the welldocumented asymmetric volatility puzzle and the effect of political uncertainty on stock market fluctuations via the investor attention channel. The results also suggest that political risk exposure could be a contributing factor to jump risk in the cross-section of returns.
\end{abstract}

Keywords: Aggregate Realized Volatility; Firm-Level Political Risk, Quantile Causality, S\&P 500. JEL Codes: C22, G1.

\section{Introduction}

The determinants of stock market volatility have been examined in numerous studies from many different angles and using various methodologies. In particular, volatility asymmetry, a welldocumented phenomenon that relates to the asymmetric effect of news on volatility, has remained a puzzle despite the overwhelming evidence of its presence in various settings including equity markets (e.g. Bekaert and Wu 2000), commodities (e.g. Morana 2001) and currencies (e.g. French et al. 1987). Although the "leverage effect" in which decreasing stock prices drive the riskiness of equity has been initially proposed to explain this phenomenon (e.g. Black, 1976), other studies have proposed a "volatility feedback" mechanism in which high volatility depresses returns (e.g. Campbell and Hentschel, 1992; Bekaert and Wu, 2000). More recently, however, building on the evidence by Andrei and Hasler (2015) that investor attention is related to volatility, Dzieliński et al. (2018) argue that volatility asymmetry is largely driven by asymmetries in investor attention channelled by the differences in opinion and dispersion in forecasts. Motivated by a growing number of studies on the effect of economic policy uncertainty (EPU) on stock market volatility (e.g. Pastor and Veronesi, 2012, 2013), we contribute to this debate from a novel angle. Utilizing the concept of political risk exposure at the firm level, recently developed by Hassan et al. (2017), we explore the role of political risk on volatility asymmetry in stock market returns. By doing so, we contribute to the literature on (i) volatility asymmetry by providing an alternative risk-based explanation to its cause; and (ii) the EPU-stock market nexus by exploring an alternative channel in which volatility might be related to political uncertainty.

\footnotetext{
* Department of Economics, University of Pretoria, Pretoria, South Africa. Email: goodness.aye@gmail.com.

** Department of Economics, Eastern Mediterranean University, Famagusta, via Mersin 10, Northern Cyprus, Turkey; Department of Economics, University of Pretoria, Pretoria, 0002, South Africa; Montpellier Business School, Montpellier, France. Email: mehmet@mbalcilar.net.

*** Corresponding author. Department of Economics and Finance, Southern Illinois University Edwardsville, Edwardsville, IL 62026- 1102, USA. Email: rdemire@siue.edu.

**** Department of Economics, University of Pretoria, Pretoria, South Africa. Email: rangan.gupta@up.ac.za.
} 
Clearly, accurate prediction of the process of volatility (both at firm- and aggregate-levels) has implications for portfolio selection, the pricing of derivative securities and risk management (Poon and Granger, 2003; Rapach and Strauss, 2008; Rapach et al., 2008). In addition, financial market volatility, as witnessed during the recent global crisis, can have wide repercussions on the economy as a whole, via its effect on real economic activity and public confidence. Hence, estimates of market volatility can serve as a measure for the vulnerability of financial markets and the economy, and can help policymakers design appropriate policies. Not surprisingly, the literature on modelling and prediction of volatility is well established (see, Babikir et al., 2010; Ben Nasr et al., 2014, 2016; Gil-Alana et al., 2014; Yaya et al., 2015 for detailed reviews).

While volatility prediction has historically relied on high-frequency univariate models, more recently, Engle and Rangel (2008), Rangel et al., (2011) and Engle et al. (2013) have highlighted the importance of low-frequency financial and macroeconomic variables in capturing future movements in the volatility process of financial assets, based on mixed-frequency modelling. In this context, Hassan et al. (2017) adapt simple tools from computational linguistics to construct a new measure of political risk faced by individual U.S. firms, i.e., the share of their quarterly earnings conference calls that they devote to political risks. They then show that this proxy of political risk is able to predict quarterly (implied and realized) U.S. firm-level volatility in a panel of 9,481 firms. While Hassan et al. (2017) relate the effect of political risk on volatility to market frictions and inefficiencies that hinder growth at the firm level, the recent evidence by Andrei and Hasler (2015) and Dzieliński et al. (2018) create an interesting opening suggesting that investor attention and dispersion of forecasts by analysts may also play a role in how political risk exposure relates to volatility.

Against this backdrop, this paper examines whether the cross-sectional average and standard deviation of firm-level political risk exposures over time can predict overall, good and bad realized volatilities of aggregate stock market returns. This is an important concern as Giot et al. (2010) stresses that financial market participants care not only about the nature of volatility, but also of its level, with all traders making the distinction between good and bad volatilities, which in turn, provides us the motivation to look at such disaggregation of the volatility process. For our purpose, we use the nonparametric causality-in-quantiles test of Jeong et al. (2012) to examine the predictability of quarterly realized volatilities of the S\&P 500 returns emanating from the firm-level political risk exposures. The causality-in-quantile approach has two novelties: First, it is robust to misspecification errors as it detects the underlying dependence structure between the examined time series, which could prove to be particularly important as it is well known that S\&P 500 equity market realized volatility is nonlinearly related with its predictors (Balcilar et al., 2018). ${ }^{1}$ Second, via this methodology, we are able to test for causality over the entire conditional distribution of the dependent variable, which is particularly important if the dependent variable has fat-tails - as is the case for realized volatility of the S\&P 500 financial returns (Gupta et al., 2018). ${ }^{2}$ Consequently, the ability of our method to accommodate for nonlinearity and go beyond the causality at the conditional-mean, makes the quantile based approach a more general one, and hence, enhances the possibility of detecting predictability by controlling for misspecification. To the best of our knowledge, this is the first paper that examines causal interactions between the dispersion of firm-level political risk exposures and the realized volatility of the S\&P 500 using a causality-in-quantile approach. The remainder of the

\footnotetext{
${ }^{1}$ When we applied the Brock et al., (1996, BDS) test, we detected nonlinear relationship between realized volatilities and the mean and standard deviation of the firm-level political risk variables. Complete details of these results are available upon request from the authors.

2 The Jarque-Bera test of normality, details of which are available upon request from the authors, overwhelmingly rejected the null of normality for the realized volatilities, resulting from positive skewness and excess kurtosis.
} 
paper is organized as follows: Section 2 outlines the methodology, Section 3 discusses the data and results, and Section 4 concludes.

\section{Methodology}

The causality-in-quantiles test employed in this study builds on Jeong et al. (2012). Our dependent variable $\left(y_{t}\right)$ is the quarterly realized aggregate, good or bad volatility of the S\&P500 index, which is obtained from the daily sum of squared log-returns, positive only log-returns or negative only log-returns over a specific quarter, respectively. The predictor variable $\left(x_{t}\right)$ is the mean, the cross-sectional mean or dispersion of firm-level political risk exposures employed one at a time (discussed in detail in the data segment). Let $Y_{t-1} \equiv\left(y_{t-1}, \ldots, y_{t-p}\right), X_{t-1} \equiv\left(x_{t-1}, \ldots, x_{t-p}\right)$ with $Z_{t}=\left(X_{t}, Y_{t}\right)$ and $F_{y_{t} \mid Z_{t-1}}\left(y_{t}, Z_{t-1}\right)$ and $F_{y_{t} \mid Y_{t-1}}\left(y_{t}, Y_{t-1}\right)$ denote the conditional distribution functions of $y_{t}$ given $Z_{t-1}$ and $Y_{t-1}$, respectively. Denoting $Q_{\theta}\left(Z_{t-1}\right) \equiv Q_{\theta}\left(y_{t} \mid Z_{t-1}\right)$ and $Q_{\theta}\left(Y_{t-1}\right) \equiv Q_{\theta}\left(y_{t} \mid Y_{t-1}\right)$, we have $F_{y_{t} \mid Z_{t-1}}\left\{Q_{\theta}\left(Z_{t-1}\right) \mid Z_{t-1}\right\}=\theta$ with probability one. As a result, the (non)causality in the -th quantile hypotheses to be tested are:

$$
\begin{aligned}
& H_{0}: P\left\{F_{y_{t} \mid Z_{t 1}}\left\{Q\left(Y_{t 1}\right) \mid Z_{t 1}\right\}=\right\}=1, \\
& H_{1}: \quad P\left\{F_{y_{t} \mid Z_{t 1}}\left\{Q\left(Y_{t 1}\right) \mid Z_{t 1}\right\}=\right\}<1 .
\end{aligned}
$$

Jeong et al. (2012) use the distance measure $J=\left\{\varepsilon_{t} E\left(\varepsilon_{t} \mid Z_{t-1}\right) f_{z}\left(Z_{t-1}\right)\right\}$, where $\varepsilon_{t}$ is the regression error term and $f_{z}\left(Z_{t-1}\right)$ is the marginal density function of $Z_{t-1}$. The regression error $\varepsilon_{t}$ emerges based on the null hypothesis in (1), which can only be true if and only if $E\left[1\left\{y_{t} \leq Q_{\theta}\left(Y_{t-1}\right) \mid Z_{t-1}\right\}\right]=\theta$ or, expressed in a different way, $1\left\{y_{t} \leq Q_{\theta}\left(Y_{t-1}\right)\right\}=\theta+\varepsilon_{t}$, where $\mathbf{1}\{\rtimes$ is the indicator function. Jeong et al., (2012) show that the feasible kernel-based sample analogue of $J$ has the following format:

$$
\hat{J}_{T}=\frac{1}{T(T 1) h^{2 p}} \sum_{t=p+1}^{T} \sum_{s=p+1, s \neq t}^{T} K\left(\frac{Z_{t 1} Z_{s 1}}{h}\right) \hat{t s} .
$$

where $K(\cdot)$ is the kernel function with bandwidth $h, T$ is the sample size, $p$ is the lag order, and ${ }_{t}$ is the estimate of the unknown regression error, which is given by

$$
\hat{t}_{t}=1\left\{y_{t} Q\left(Y_{t 1}\right)\right\} \text {. }
$$

$\hat{Q}_{\theta}\left(Y_{t-1}\right)$ is an estimate of the $\theta^{\text {th }}$ conditional quantile of $y_{t}$ given $Y_{t-1}$, and we estimate $\hat{Q}_{\theta}\left(Y_{t-1}\right)$ using the nonparametric kernel method as

$$
\hat{Q}_{\theta}\left(Y_{t-1}\right)=\hat{F}_{y_{t} \mid Y_{t-1}}^{-1}\left(\theta \mid Y_{t-1}\right)
$$

where $\hat{F}_{y_{t} \mid Y_{t-1}}\left(y_{t} \mid Y_{t-1}\right)$ is the Nadarya-Watson kernel estimator given by

$$
\hat{F}_{y_{t} \mid Y_{t 1}}\left(y_{t} \mid Y_{t 1}\right)=\frac{{ }_{s=p+1, s t}^{T} L\left(\left(\begin{array}{lll}
Y_{t 1} & Y_{s 1}
\end{array}\right) / h\right) 1\left(\begin{array}{ll}
y_{s} & y_{t}
\end{array}\right)}{T},
$$

with $L(\cdot)$ denoting the kernel function and $h$ the bandwidth.

The empirical implementation of causality testing via quantiles entails specifying three key parameters: the bandwidth $(b)$, the lag order $(\phi)$, and the kernel type for $K(\cdot)$ and $L(\cdot)$. We use a lag order of one based on the Schwarz information criterion (SIC), which is known to select a 
parsimonious model as compared with other lag-length selection criteria, and hence, help us overcome the over-parameterization problem that typically arises in studies using nonparametric frameworks, and particularly in our case with 64 observations. For each quantile, we determine the bandwidth parameter $(b)$ by using the leave-one-out least-squares cross validation method. Finally, for $K(\cdot)$ and $L(\cdot)$, we use Gaussian kernels.

\section{Data and Empirical Results}

Our analysis is based on two variables, namely, the quarterly (overall, good, or bad) realized volatility of the S\&P500 returns (RV, RV-Good, or $\mathbf{R V - B a d )}$ and the cross-sectional average and dispersion (standard deviation) of political risk exposures across firms. Since the data on the firm-level political risk is available only quarterly, our analysis covers the period of 2001:01 to 2016:04. Note that the start and end dates are purely driven by the availability of firm-level political risk data.

Hassan et al., (2017) use textual analysis of quarterly earnings conference-call transcripts to construct a firm-level measure of the extent and type of political risk faced by individual firms listed in the U.S. exchanges. This metric is simply based on the share of the conversation between participants and firm management that centers on risks associated with politics, i.e., PRisk. To this end, they adapt a simple pattern-based sequence-classification method developed in computational linguistics in order to distinguish between language associated with political versus non-political topics. For each of 9,481 firms listed on a U.S. stock exchange between 2001 and 2016, the dataset not only provides information for PRisk, but also its two logical components: (1) A measure of political exposure, PolX, calculated by counting only the number of political bigrams, without conditioning on risk, and; (2) A measure of overall risk, Risk, calculated by counting only the number of synonyms for risk or uncertainty, without conditioning on political bigrams. In addition, the dataset lists NPRisk, a measure of nonpolitical risk faced by each firm in each quarter, constructed by calculating the weighted sum of non-political bigrams used in conjunction with a synonym for risk or uncertainty. ${ }^{3}$

Since the firm-level political risk data is available quarterly, we compute the quarterly realized volatility of the S\&P 500 using daily data sourced from the Global Financial Database. The measure that we consider is the classical estimator of realized volatility, i.e. the sum of squared daily returns (Andersen and Bollerslev, 1998), expressed as: $R V_{t}=\sum_{i=1}^{M} r_{t, i}^{2}$, where $r_{t, i}$ is the daily $M \times 1 \log$-return vector and $i=1, \ldots, M$ the number of daily returns over a quarter. $\mathrm{RV}$ Good (RV-Bad) is obtained by considering daily positive (negative) log-returns only, using the same formula above. With both RV and the various political risk variables being stationary, based on standard unit root tests ${ }^{4}$, we do not require any further transformations to conduct our quantile causality tests which require stationary data. Given that we want to predict aggregate volatility, our measure of political risk is the cross-sectional average (_Mean) and standard deviation (_SD) of firm-level political risk metrics across the 9,481 firms in the sample.

Figures 1(a), 1(b), and 1(c) present the results obtained from the quantile causality tests for overall (RV), good (RV-Good), and bad (RV-Bad) volatility, respectively due to the various political risk metrics, namely PRisk_Mean, PRisk_SD, PolX_Mean, PolX_SD, Risk_Mean, Risk_SD, NPRisk_Mean, and NPRisk_SD, over the quantile range of 0.05 to 0.95 . In the figures, the line corresponding to each political risk variable shows the rejection (non-rejection) of the

\footnotetext{
${ }^{3}$ Further details involved in the construction of the data, and the data set itself is available for download from: http://www.policyuncertainty.com/firm pr.html.

${ }^{4}$ Complete details of the unit root tests are available upon request from the authors.
} 
null of no Granger causality from the political risk variable to each S\&P 500 realized volatility measure at a specific quantile captured in the horizontal axis. Note that, as in Hassan et al., (2017), for the sake of comparability, we also include the economy-wide news-based measure of economic policy uncertainty (EPU) index (as developed by Baker et al., 2016) in our set of predictors. ${ }^{5}$ Given that the test statistic is standard normal, the figures also present the lines capturing the critical values of $2.575,1.96$, and 1.645 across the quantiles corresponding to $10 \%$, $5 \%$, and $1 \%$ levels of significance respectively.

Figure 1(a). Causality-in-Quantiles Test Result for Overall Realized Volatility (RV) of the S\&P 500

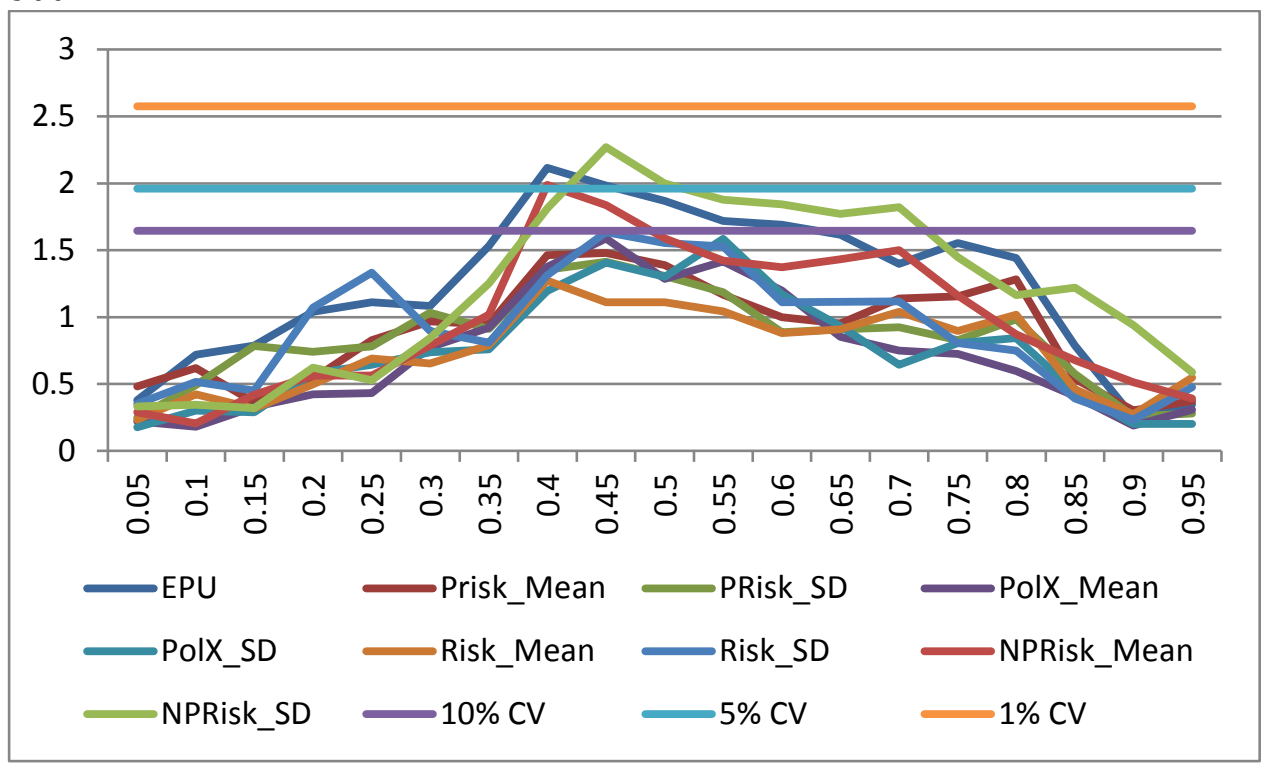

Figure 1(b). Causality-in-Quantiles Test Result for Good Realized Volatility (RV-Good) of the S\&P 500

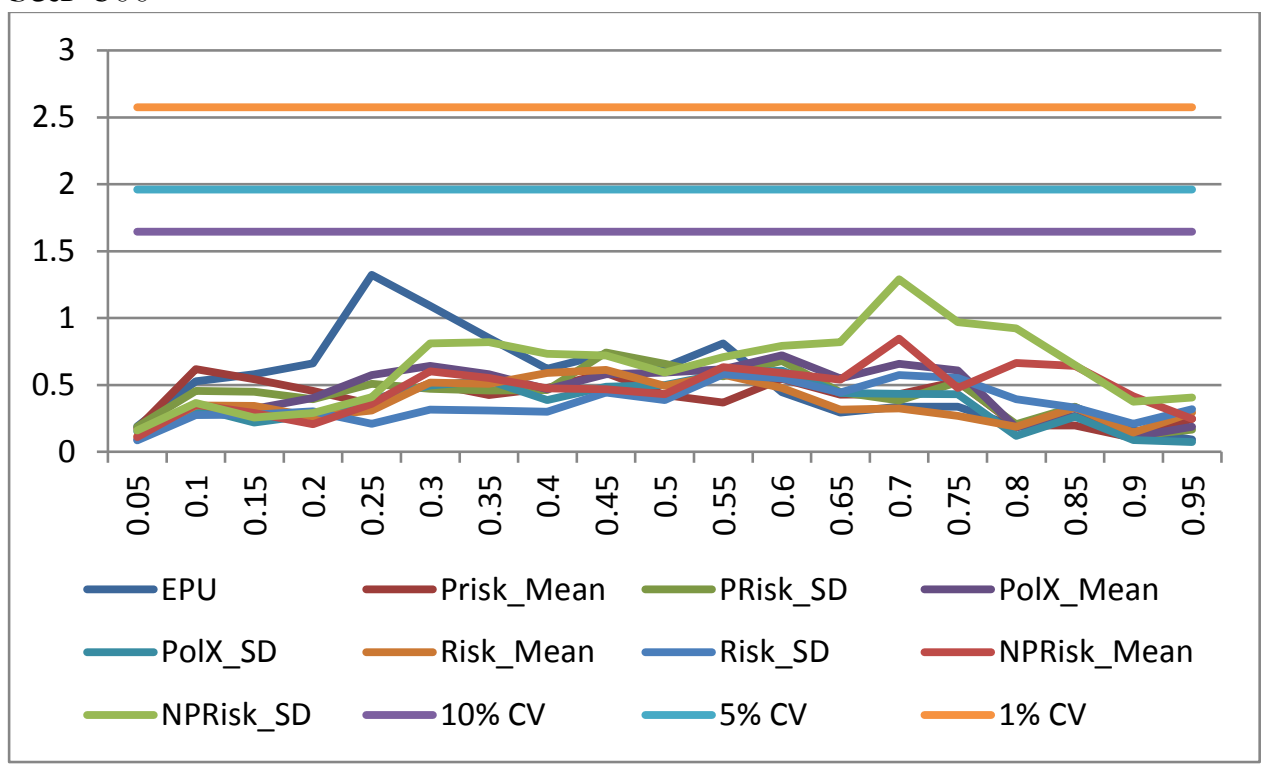

5 The data is downloaded from: http://www.policyuncertainty.com/us monthly.html, with the weblink also providing details on the construction of this EPU index. Note the EPU index is available at monthly frequency, which we convert to quarterly values based on temporal aggregation, i.e., taking the average over three months of a specific quarter. 
Figure 1(c). Causality-in-Quantiles Test Result for Bad Realized Volatility (RV-Bad) of the S\&P 500

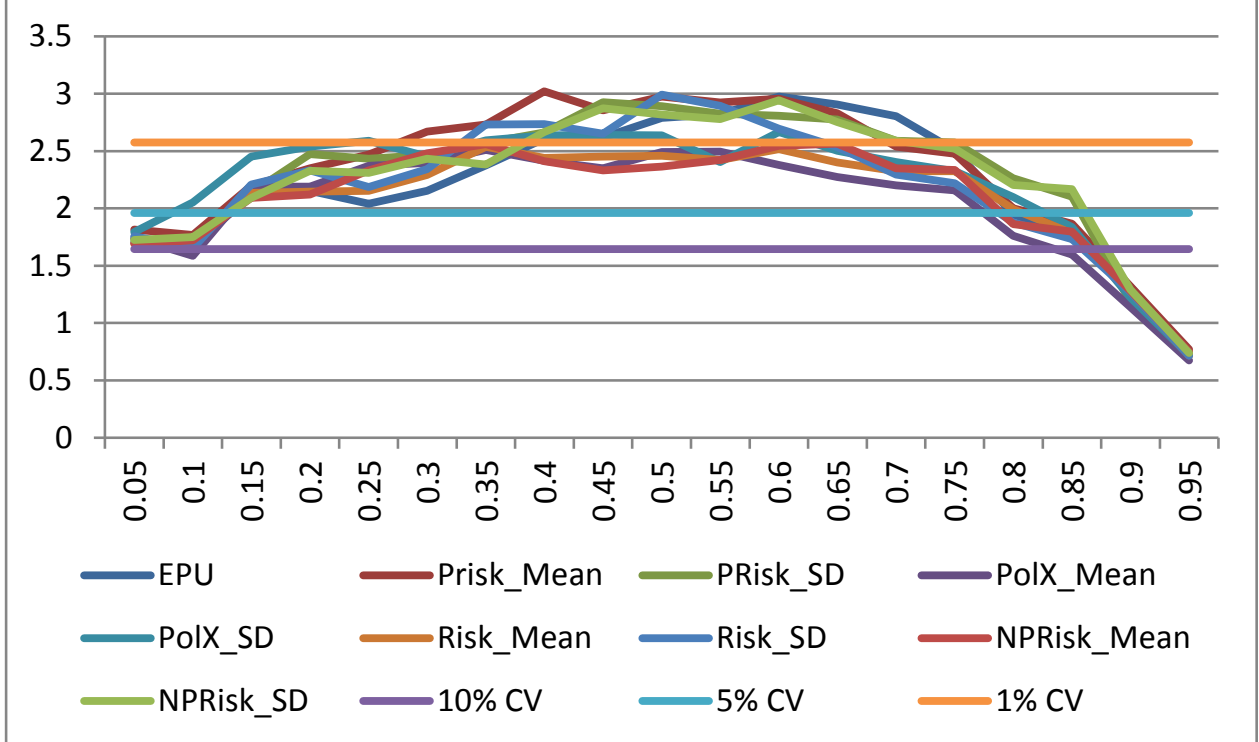

Note: The vertical axis presents the test statistics corresponding to the null hypothesis that a given political risk metric (PRisk_Mean, PRisk_SD, PolX_Mean, PolX_SD, Risk_Mean, Risk_SD, NPRisk_Mean, and NPRisk_SD) does not Granger cause S\&P500 realized volatility measure (RV, RV-Good, and RV-Bad). Horizontal axis captures the quantiles. The line corresponding to each political risk variable shows the rejection (non-rejection) of the null of no Granger causality from the political risk variable to the S\&P 500 realized volatility measure at the 10,5, or 1 percent levels of significance if the lines are above (below) 1.645, 1.96 , or 2.575 for a specific quantile captured in the horizontal axis. $10 \% \mathrm{CV}, 5 \% \mathrm{CV}$, and $1 \% \mathrm{CV}$ are the 10, 5 and 1 percent critical values of 1.645, 1.96, and 2.575, respectively.

As can be seen from Figure 1(a), predictability for RV is only restricted to EPU over the quantile range of 0.40-0.60, and under NPRisk_Mean and NPRisk_SD for the quantiles 0.40-0.45 and 0.40-0.70. This suggests that neither political risk proxy has a causal effect on the overall realized volatility of stock market returns. However, comparing the results for good and bad volatility, we see that the predictive power of political risk proxies largely concentrate on the bad volatility measure. While we observe in Figure 1(b) no evidence of predictability either from EPU or any of the political risk variables, the results presented in Figure 1(c) display clear and highly significant evidence of predictability for bad volatility (RV-Bad) from all of the predictors (EPU and firm-level based political risks), over the entire conditional distribution of bad volatility, except at the extreme upper end (0.90-0.95) of the conditional distribution. ${ }^{6}$ Note that we use standardized version (i.e., standard deviation of the variables normalized to unity) of the predictors, to check for the relative strength of causality emanating from the predictors. Given this, we observe that the predictors, in general, perform equally well (or equally poorly).

While observing similar results for the economic policy uncertainty index and the various firm level political risk proxies in our tests reinforces the validity of the individual firm level measures

\footnotetext{
${ }^{6}$ We also used bootstrapped linear Granger causality tests designed for modest sample sizes as in Balcilar et al., (2010), and Ashley and Tsang (2014). However, these tests failed to pick up any evidence of predictability for the various realized volatilities (even at the $10 \%$ level of significance), which is not surprising, given that these models are misspecified due to the existence of nonlinearity as discussed in footnote 1. However, some evidence of predictability from the political risk variables, especially for RV-Bad was detected when we applied rolling version of these tests, which is understandable, given that rolling-causality accounts for nonlinearity by allowing the model parameters to vary over the rolling window. Complete details of these results are available upon request from the authors.
} 
as proxies of aggregate political risk, the findings that causality is largely directed towards bad volatility suggests several important implications. Given the evidence by Hassan et al. (2017) that political shocks appear to be a significant source of firm-level (idiosyncratic) risk and that the distribution of firm-level political risk has high variance and a fat right tail, our strong findings on bad volatility suggest that political risk exposure at the firm level can induce volatility jumps that have been well-documented in financial returns (e.g. Barndorff-Nielsen and Shephard, 2004; Giot, 2010). Furthermore, given the evidence by Dunham and Friesen (2007) that jump risk can serve as a systematic risk factor in stock returns, one can argue that the causation from political risk exposure to bad volatility could be a factor driving the time-variation in risk premia.

At the same time, why the causal effect of political risk exposure is limited to bad volatility alone could be explained by piecing together the evidence from various studies in the literature. Focusing on investor attention, Andrei and Hasler (2015) relates stock market volatility to the level of attention investors pay to news such that attentive investors immediately incorporate new information to prices, driving volatility, while investors who pay little attention to news only gradually price the new information, resulting in low volatility. Keeping this in mind, in a related study from the political science literature, Soroka (2006) examine the public reaction to mass media content regarding the economy and show that public responses to negative economic information are much greater than are public responses to positive economic information. Considering the conclusion by Soroka (2006) that such an asymmetry in the public's response to economic information is in part driven by asymmetries evident in media content, resulting in mass media overemphasizing negative information, one can argue that investors' greater attention to negative information regarding political risk exposures drives the asymmetric effect that we observe in our tests. This explanation is in fact supported by the recent finding by Dzieliński et al. (2018) that volatility asymmetry is driven by asymmetric attention such that investor attention and differences of opinion drives the asymmetry in stock return volatility. Given the conclusion by Hassan et al. (2017) that political shocks serve as a significant driver of firm-level (idiosyncratic) risk and by Dzieliński et al. (2018) that stocks for which volatility is largely idiosyncratic also show a larger volatility asymmetry, our finding suggest that the effect of political risk exposure on asymmetric volatility can be explained by investor attention to economic news.

Considering the investment implications, as pointed out by Caporin et al., (2016), good volatility is directional, persistent and relatively easy to predict, while bad volatility is jumpy and comparatively difficult to foresee. Therefore, good volatility is generally associated with the continuous and persistent part, while bad volatility captures the discontinuous and jump component of volatility. To that end, our results seem to suggest that the firm-level political risk exposures affect the jump component of volatility, and in the process move bad realized volatility (see for example, Gkillas et al., 2018 who relates jumps in the Dow Jones Industrial Average (DJIA) with global geopolitical risks). This result in turn, justifies the need to distinguish between good and bad volatilities important.

\section{Conclusion}

Financial market volatility is used as an important input in investment decisions, option pricing and financial market regulation, thus making volatility prediction an important area of research for academics, investors and policymakers. In this paper, we use a nonparametric causality-inquantiles test to analyze the predictability of overall, good and bad realized volatilities of S\&P 500 index returns based on information from various proxies of political risk exposure at the firm level. This nonparametric approach not only guards against misspecification due to nonlinearity, but also tests for causality over the entire conditional distribution of the realized volatilities. Our findings indicate that political risk exposure can serve as a strong predictor of 
bad realized volatility, while the causal effects are non-existent in the case of overall and good realized volatilities.

Our findings provide further insight to the well-documented asymmetric volatility puzzle and the effect of political uncertainty on stock market fluctuations via the investor attention channel. The results also suggest that proxies of political risk exposure, either at the firm or aggregate level, should be considered in volatility forecasting models, however, only after distinguishing between good and bad components of volatility, and that political risk exposure could be a contributing factor to jump risk in the cross-section of returns.

\section{References}

Andersen T.G., and Bollerslev T. (1998). Answering the skeptics: yes, standard volatility models do provide accurate forecasts. International Economic Review, 39 (4), 885-905.

Andrei, D., Hasler, M., 2015. Investor attention and stock market volatility. Rev. Financ. Stud. 28 (1), 33-72.

Ashley, R.A., and Tsang, K.P. (2014). Credible Granger-Causality Inference with Modest Sample Lengths: A Cross-Sample Validation Approach. Econometrics, 2, 72-91.

Babikir, A., Gupta, R., Mwabutwa, C., and Owusu-Sekyere , E. (2012). Structural Breaks and GARCH Models of Stock Return Volatility: The Case of South Africa. Economic Modelling, 29(6), 2435-2443.

Baker, S. R., Bloom, N., and Davis, S. J. (2016). Measuring economic policy uncertainty. The Quarterly Journal of Economics, 131(4), 1593-1636.

Balcilar, Demirer, R., Gupta, R., and Wohar, M.E. (2018). Differences of Opinion and Stock Market Volatility: Evidence from a Nonparametric Causality-in-Quantiles Approach. Journal of Economics and Finance, 42(2), 339-351.

Balcilar, M., Ozdemir, Z.A., and Arslanturk, Y. (2010). Economic growth and energy consumption causal nexus viewed through a bootstrap rolling window. Energy Economics, 32(6), 1398-1410.

Barndorff-Nielsen, O.E., Shephard, N., 2004. Power and bipower variation with stochastic volatility and jumps. J. Financ. Econ. 2, 1-37.

Bekaert, G., Wu, G., 2000. Asymmetric Volatility and Risk in Equity Markets. Review of Financial Studies, 13, 1-42.

Ben Nasr, A. Ajmi, A.N., and Gupta, R. (2014). Modeling the Volatility of the Dow Jones Islamic Market World Index Using a Fractionally Integrated Time Varying GARCH (FITVGARCH) Model. Applied Financial Economics, 24(14), 993-1004.

Ben Nasr, A. Lux, T., Ajmi, A.N., and Gupta, R. (2016). Forecasting the volatility of the Dow Jones Islamic stock market index: Long memory vs. regime switching. International Review of Economics and Finance, 45(1), 559-571.

Black, F., 1976. Studies of stock price volatility changes. In: Proceedings of the 1976 Meetings of the Business and Economic Statistics Section, American Statistical Association, 177-181.

Brock, W., Dechert, D., Scheinkman, J., LeBaron, B., 1996. A test for independence based on the correlation dimension. Econometric Reviews, 15, 197-235.

Campbell, J., Hentschel, L., 1992. No news is good news: An asymmetric model of changing volatility in stock returns. J. Financ. Econ. 31, 281-318.

Caporin, M., Rossi, E., and Santucci de Magistris, P. (2016). Volatility jumps and their economic determinants. Journal of Financial Econometrics, 14(1), 29-80.

Dzieliński, M., Rieger, M. O., Talpsepp, T. 2018. Asymmetric attention and volatility asymmetry. Journal of Empirical Finance 45, 59-67.

Dunham, L.M., Friesen, G.C., 2007. An empirical examination of jump risk in U.S. equity and bond markets. N. Am. Actuar. J. 11 (4), 76-91. 
Engle, R.F. (1982). Autoregressive conditional heteroskedasticity with estimates of U.K. inflation. Econometrica, 50, 987-1008.

Engle, R.F., and Rangel, J.G. (2008). The Spline-GARCH Model for Low-Frequency Volatility and Its Global Macroeconomic Causes. Review of Financial Studies 21(3), 1187-1222.

Engle, R.F., Ghysels, E., and Sohn, B. (2013). Stock Market Volatility and Macroeconomic Fundamentals. The Review of Economics and Statistics 95(3), 776-797.

French, K., et al., 1987. Expected stock returns and volatility. J. Financ. Econ. 19 (1), 3-29.

Gil-Alana, L.A., Shittu, O.I. and Yaya, O.S. (2014). On the persistence and volatility in European, American and Asian stocks bull and bear markets, Journal of International Money and Finance, 40(C), 149-162.

Giot, P., Laurent, S., and Petitjean, M. (2010). Trading activity, realized volatility and jumps. Journal of Empirical Finance, 17(1), 168-175.

Gkillas, K., Gupta, R., and Wohar, M.E. (2018). Volatility jumps: The role of geopolitical risks. Finance Research Letters. DOI: https://doi.org/10.1016/j.frl.2018.03.014.

Gupta, R., Pierdzioch, C., Selmi, R., and Wohar, M.E. (2018). Does Partisan Conflict Predict a Reduction in US Stock Market (Realized) Volatility? Evidence from a Quantile-on-Quantile Regression Model. North American Journal of Economics and Finance, 43, 87-96.

Hassan, T.A., Hollander, S., van Lent, L., and Tahoun, A. (2017). Firm-Level Political Risk: Measurement and Effects. NBER Working Paper No. 24029.

Jeong, K., Härdle, W. K. and Song, S., 2012. A consistent nonparametric test for causality in quantile. Econometric Theory, 28, 861-887.

Morana, C., 2001. A semiparametric approach to short-term oil price forecasting. Energy Econ. 23 (3), 325-338.

Pástor, L., \& Veronesi, P. 2012. Uncertainty about government policy and stock prices. The Journal of Finance, 67(4), 1219-1264.

Pástor, L., \& Veronesi, P. 2013. Political uncertainty and risk premia. Journal of Financial Economics, 110(3), 520-545

Poon, S-H, and Granger, C. W. J. (2003). Forecasting Volatility in Financial Markets: A Review. Journal of Economic Literature, 41(2), 478-539.

Rangel, J.G., and Engle, R.F. (2011). The Factor-Spline-GARCH Model for High and Low Frequency Correlations. Journal of Business \& Economic Statistics 30(1), 109-124.

Rapach, D.E., and Strauss, J.K. (2008). Structural Breaks and GARCH Models of Exchange Rate Volatility. Journal of Applied Econometrics, 23(1), 65-90.

Rapach, D.E., Strauss, J.K., and Wohar, M.E. (2008). Forecasting stock return volatility in the presence of structural breaks, in Forecasting in the Presence of Structural Breaks and Model Uncertainty, in David E. Rapach and Mark E. Wohar (Eds.), Vol. 3 of Frontiers of Economics and Globalization, Bingley, United Kingdom: Emerald (May 2008), pp. 381-416.

Soroka, S. N. 2006. Good News and Bad News: Asymmetric Responses to Economic Information. The Journal of Politics, Vol. 68, 2 (May), 372-385.

Yaya, O.S., Gil-Alana, L.A., and Shittu, O.I. (2015). Fractional Integration and Asymmetric Volatility in European, American and Asian Bull and Bear Markets: Application to Highfrequency Stock Data, International Journal of Finance \& Economics, 20(3), 276-290. 